\section{Endoscopic Demonstration of Malignant Duodenocolic Fistula: Two Case Reports}

Malignant duodenocolic fistula is a rare clinical condition. We recently encountered two patients with malignant duodenocolic fistula, in whom endoscopy could be successfully performed. In the first case, an 80-year-old male was admitted, complaining of diarrhea and weight loss. Barium meal study revealed that the contrast material proceeded to the colon through a fistula located between the duodenum and the colon. Duodenoscopy revealed a reddish nodular mass in the second portion of the duodenum, in the center of this mass an orifice of the fistula could be observed. In the second case, a 66-year-old female was referred to our hospital, complaining of diarrhea and anorexia. Barium meal study showed a fistula located between the duodenum and the colon (Figure 1). Duodenoscopy and colonoscopy revealed the orifice of the fistula (Figures $\mathbf{2}$ and $\mathbf{3}$ ).

Since the first report by Haldane (1) in 1862 , approximately 70 cases of malignant duodenocolic fistula have been described in the literature $(2,3)$, and the incidence of this condition has been estimated as only one in 900 colorectal carcinomas (4). The diagnostic value of duodenoscopy has been described previously (2). In both of our patients, the fistula's orifice in the duodenum was demonstrated endoscopically. Colonoscopy has been reported as not being helpful towards demonstrating a fistula because of difficulty in intubation of an acutely or chronically inflamed bowel segment or because of failure to reach the level of the fistula (4). Fortunately we could visualize the fistulous tract under colonoscopy in Case 2 .

\section{T. Matsumoto', M. Iida', Y. Kuwano', M. Furuse', Y. Kimura ? \\ M. Fujishima ${ }^{\perp}$}

Second Department of Internal Medicine, Faculty of Medicine, Kyushu University Maidashi 3-1-1, Higashi-ku, Fukuoka 812, Japan

${ }^{2}$ Kimura Hospital, Fukuoka, Japan

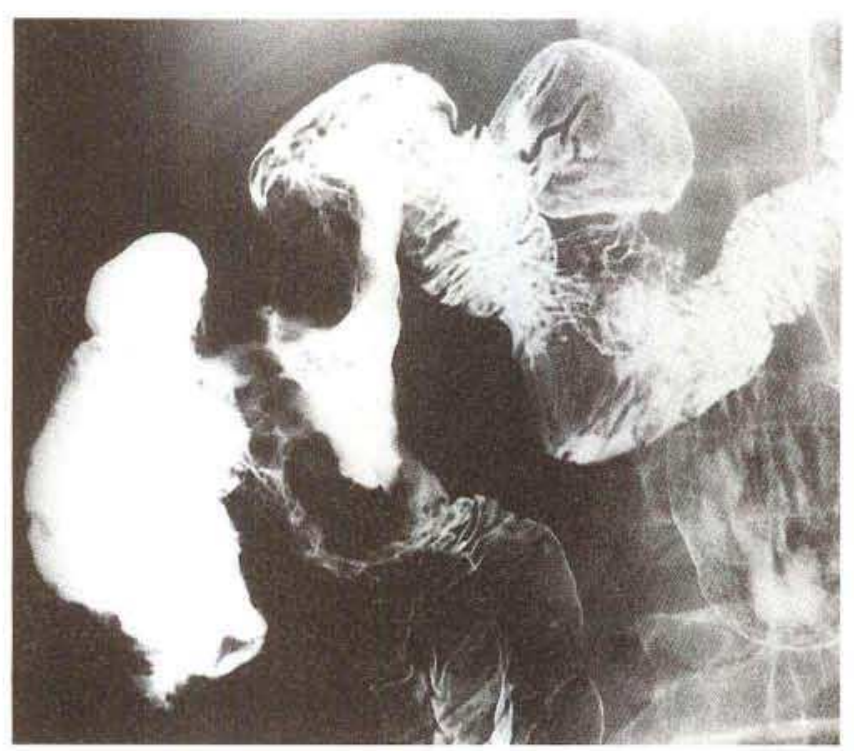

Figure 1: Barium meal study in Case 2 shows a fistula between the second portion of the duodenum and the colon. The colonic side of the fistula is surrounded by nodular elevation.

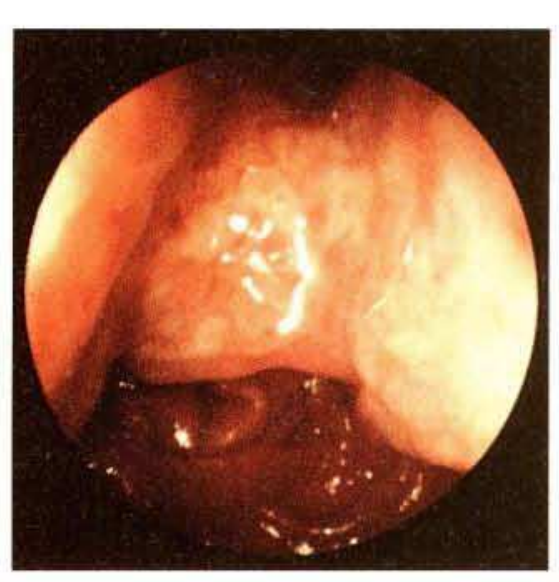

Figure 2: Duodenoscopic findings in Case 2. An orifice of the fistula with nodular elevations can be seen in the second portion of the duodenum

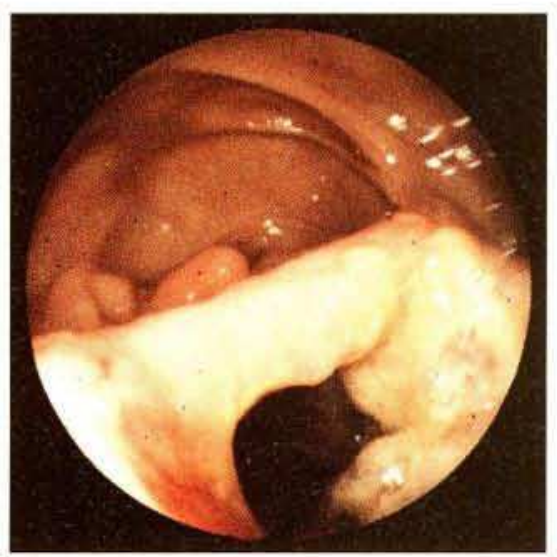

Figure 3: Colonoscopic view in Case 2. An orifice surrounded by nodular elevations can be seen. Another orifice could also be identified during colonoscopy.

\section{References}

1. Haldane DR: Case of cancer of the caecum, accompanied with cecoduodenal and cecocolic fistulae. Med J Edinburgh 1862; 7 : 624-629

2. Roberts PL, Coller JA, Corriveau S, et al.: Malignant duodenocolic fistula diagnosed by endoscopy. Surg Endose 1989; 3: $112-114$.

3. Iuchtman $M$, Zer $M$, Plavnick $Y$, et al.: Malignant duodenocolic fistula: the role of extended surgery. J Clin Gastroenterol 1993; 16: $22-25$.

4. Welch JP, Warshaw AL: Malignant duodenocolic fistulas. Am J Surg 1977; 133: 658-661.

5. Abcarian H, Udezue $N$ : Coloenteric fistulas. Dis Colon Rectum 1978; $21: 281-286$.

Corresponding Author

Takayuki Matsumoto

Second Department of Internal Medicine

Faculty of Medicine

Kyushu University

Maidashi 3-1-1, Higashi-ku

Fukuoka 812

Japan

Fax: $+81-92-6322551$ 